\title{
PROCESSO DE INDEXAÇÃO NAS BIBLIOTECAS DOS INSTITUTOS FEDERAIS DO PARANÁ - IFPR
}

INDEX PROCESS IN LIBRARIES OF THE FEDERAL INSTITUTE OF PARANÁ - IFPR

PROCESO DE INDEXACIÓN EN LAS BIBLIOTECAS DE LOS INSTITUTOS FEDERALES DEL PARANÁ - IFPR

\section{Fabiane Ferreira ${ }^{1}$ Brígida Maria Nogueira Cervantes ${ }^{2}$}

\begin{abstract}
RESUMO
A principal função das bibliotecas dos Institutos Federais está no seu papel de disseminadora da informação e facilitadora do acesso ao conhecimento registrado. Elas são responsáveis por fornecer recursos informacionais (produtos e serviços), indispensáveis à sua atuação de atender a um público diversificado. Esta pesquisa visa investigar como está sendo realizado o processo de indexação nas bibliotecas do Instituto Federal do Paraná (IFPR). A pesquisa foi classificada como exploratória e qualitativa, com a utilização de questionário para a coleta dos dados. Os resultados indicam que as bibliotecas não possuem instrumentos e formas de se organizar e controlar a atividade de indexação. Isso torna evidente a necessidade de elaboração de uma política de indexação que direcione a catalogação de assunto no contexto das bibliotecas do IFPR. Conclui-se que estas bibliotecas são singulares e encontram-se em fase inicial de formação, exigindo de seus profissionais esforços para a consolidação de políticas e diretrizes para nortear e solidificar as atividades nelas desenvolvidas.
\end{abstract}

PALAVRAS-CHAVE: Processamento da informação. Indexação. Unidades de informação

\begin{abstract}
The main function of the Federal Institutes' Libreries lies in their role as information disseminators and facilitators of access to registered knowledge. They are responsible for providing informational resources (products and services), which are absolutely necessary for their action of attending a diverse public. This research aims to investigate how the process of indexing in the libraries of the Instituto Federal do Paraná (IFPR) is being done. The research was classified as exploratory and qualitative and a questionnaire was used to collect the data. The results indicate that libraries do not have the tools and ways of organization and control the indexing activity at their disposal. It evidences the need of elaborating an indexing policy that directs the subject cataloging in the context of IFPR libraries. The conclusion is that these libraries are unique and find themselves in the beginning of their shaping phase, demanding form their professionals efforts to the consolidation of policies and guidelines in order to guide and set their ongoing activities.
\end{abstract}

KEYWORDS: Information processing. Indexing. Information units.

\section{RESUMEN}

La principal función de las bibliotecas de los Institutos Federales se encuentra en su papel de diseminadora de la información y facilitadora del acceso al conocimiento registrado. Son las responsables por ofrecer recursos informacionales (productos y servicios), indispensables en su atendimiento a un público diversificado. Esta pesquisa pretende investigar cómo está siendo realizado el proceso de indexación en las bibliotecas del Instituto

\footnotetext{
${ }^{1}$ Mestrado em andamento no Programa de Pós-graduação em Ciência da Informação da Universidade Estadual de Londrina - UEL. E-mail: fabiane.ferreira@ifpr.edu.br

${ }^{2}$ Professora Adjunto do Departamento de Ciência da Informação da Universidade Estadual de Londrina. E-mail: brigidacervantes@gmail.com
}

Enviado em: 14/10/2015 - Aceito em: 11/12/2015 
Federal del Paraná (IFPR). La pesquisa fue clasificada como exploratoria y cualitativa, con la utilización de un cuestionario para la recolección de los datos. Los resultados indican que las bibliotecas no poseen instrumentos ni formas de organización y control para la actividad de indexación. Esa situación torna evidente la necesidad de la elaboración de una política de indexación que direccione la catalogación de asunto en el contexto de las bibliotecas del IFPR. Se concluye que estas bibliotecas son singulares y se encuentran en la fase inicial de formación, exigiendo esfuerzos de sus profesionales para la consolidación de políticas y directrices para guiar y solidificar las actividades que se desarrollan en las mismas.

PALABRAS CLAVE: Procesamiento de la información. Indexación. Unidades de información.

\section{INTRODUÇÃO}

O Brasil está vivenciando a maior expansão unidades dedicadas ao ensino técnico e tecnológico, investindo de forma bastante positiva na construção dos Institutos Federais de Educação, Ciência e Tecnologia, mais conhecidos como Institutos Federais. Estes Institutos foram criados por meio da Lei Federal n ${ }^{\circ} 11.892$ de 28 de dezembro de 2008, são vinculados ao Ministério da Educação, distribuídos por todo o território brasileiro e funcionam com estrutura multicampi, oferecendo cursos de educação básica, profissional e educação superior (BRASIL, 2008).

Em 2008, os Institutos Federais passaram a ter relevância similar às universidades federais, destacando-se pela autonomia e abrangência pedagógica verticalizada, e atuando em cursos técnicos, principalmente na modalidade integrada com o ensino médio, licenciaturas, graduações tecnológicas e pós-graduações voltadas principalmente para a pesquisa aplicada na área de inovação tecnológica.

O Instituto Federal do Paraná (IFPR) faz parte dos 38 institutos federais existentes no país, originou-se da Escola Técnica da Universidade Federal do Paraná (ET-UFPR), e possui mais de 30 mil estudantes nos cursos de modalidade presencial e à distância.

O IFPR é constituído por 13 campi, além de 7 campi que se encontram em fase de implantação. O IFPR é formado também pelas Unidades de Educação Profissional (UEPs), que são unidades especializadas na oferta de ensino técnico, cursos de formação inicial e continuada e de Educação a Distância, atendendo, prioritariamente, as ações que integram o Programa Nacional de Acesso ao Ensino Técnico e Emprego (Pronatec).

Nos campi dos Institutos são oferecidos cursos voltados às necessidades profissionais, sociais e culturais das regiões onde estão implantados, os quais atendem a uma gama de usuários bem diferenciados. Em função disso, suas bibliotecas devem atuar como agentes fundamentais na concretização da sua missão, fomentando suas atividades de ensino, pesquisa e extensão.

A comunidade diversificada de usuários das bibliotecas dos Institutos é composta pelos alunos dos cursos do ensino médio integrado ao técnico, ensino técnico, ensino superior e pós-graduação, além dos docentes e servidores técnico-administrativos, o que torna necessário dotar cada campus com recursos informacionais (produtos e serviços) necessários a sua atuação e que atendam aos diversos públicos. 
Em razão da diversificação dos usuários das bibliotecas dos Institutos, torna-se fundamental que os bibliotecários representem tematicamente os documentos, a fim de atender as diferentes necessidades informacionais destes usuários, ou seja, que a indexação realizada nessas bibliotecas seja eficiente o bastante para que possibilite a todos estes usuários o acesso aos documentos por eles pesquisados.

Diante dessa realidade, este trabalho buscou investigar como é realizado o processo de indexação nas bibliotecas do IFPR. Para isso, fez-se necessário: identificar quem atua na indexação; verificar a existência de processos e condutas sistematizadas e adequadas que orientem a atividade de indexação; buscar conhecer a compreensão dos bibliotecários referente à importância do processo da indexação; verificar se há uma política de indexação e quais aspectos, na opinião dos bibliotecários, devem ser contemplados para uma política de indexação eficiente para a rede de bibliotecas do IFPR.

Portanto este estudo vem ressaltar a compreensão de que o bibliotecário é responsável por promover o acesso do usuário ao documento, na medida em que trata a informação, com fins de disseminá-la de maneira adequada.

\section{REFERENCIAL TEÓRICO}

\subsection{As Bibliotecas no Contexto dos Institutos Federais}

Os Institutos Federais são instituições portadoras de características singulares, com estrutura multicampi, contemplam diferentes modalidades de ensino em uma única Instituição, podendo ofertar desde cursos de qualificação profissional até pós-graduações. Dentro desse contexto organizacional estão inseridas suas respectivas bibliotecas. (HOFFMANN, BOCCATO, SANTOS, 2011)

As bibliotecas atendem a uma comunidade de usuários diversificada, abarcada pelo tripé ensino, pesquisa e extensão, portanto devem prestar assessoria aos processos de ensinoaprendizagem, aos processos investigativos e aos processos extensionistas de cada campus, oferecendo infraestrutura informacional adequada e de qualidade.

Pode-se inferir, de acordo com Hoffmann, Boccato, Santos (2011, p.130), que as bibliotecas dos Institutos congregam uma junção de diferentes tipologias de bibliotecas, tais como:

Biblioteca universitária: os Institutos Federais podem ofertar cursos superiores em tecnologia, licenciaturas e pós-graduação lato sensu e stricto sensu;

Biblioteca escolar: os Institutos Federais podem ofertar cursos técnicos integrados ao ensino médio;

Biblioteca especializada: acervo especializado em suas respectivas áreas de atuação, de acordo com a oferta de cursos.

Nesse contexto dos Institutos vislumbra-se um novo conceito tipológico de bibliotecas, assim como um novo perfil de bibliotecário, que deverá atuar em diferentes setores da biblioteca, inclusive na catalogação do acervo, mais especificamente no tratamento 
temático dos documentos.

Diante da realidade das bibliotecas dos IFs, fica evidente a importância que deve ser dada ao tratamento temático da informação, especificamente ao processo de indexação, ou seja, faz-se necessário a compreensão da importância da indexação de assuntos condizentes com a realidade das bibliotecas.

\subsection{O Tratamento e a Representação Temática da Informação no Contexto da Biblioteca}

Para a recuperação e acesso à informação nas bibliotecas, é fundamental a sua organização. Esse processo compreende a catalogação, a classificação e a indexação, que são realizadas por etapas específicas, de acordo com regras, normas e políticas adotadas pela instituição.

Maimome, Silveira e Tálamo (2011), destacam que a representação da informação divide-se em representação descritiva e representação temática. A primeira refere-se as características específicas do documento, denominada descrição bibliográfica, a qual possibilita a individualização do documento, nesta representação são definidos e padronizados os pontos de acesso, responsáveis pela busca e recuperação da informação. A segunda detém-se na representação dos assuntos dos documentos a fim de aproximá-los, facilitando a recuperação de materiais relevantes que dizem respeito a temas semelhantes.

Portanto, anterior ao processo de transferência e recuperação da informação, é necessário considerar o tratamento, que provém da necessidade de representar os documentos para disponibilizá-los à comunidade usuária de maneira tratada. Salvo contrário, o acervo de uma biblioteca estaria abnegado ao acaso, formando um conglomerado de informações dispersas.

Para Fujita (2003), a organização da informação abrange as atividades e operações do tratamento da informação, envolvendo para isso o conhecimento teórico e metodológico disponível tanto para o tratamento descritivo quanto para o tratamento temático da informação.

Nas bibliotecas, o tratamento descritivo, refere-se propriamente à catalogação, fase em que é realizada a descrição do documento, como: autor, título, edição, editora, data, número de páginas, entre outros. Já o tratamento temático refere-se ao conteúdo tratado no documento, que compreende as atividades de classificação e indexação de assunto.

Sendo assim, o bibliotecário deve empregar esforços na análise de assunto. Essa análise não deve ser influenciada pelo uso de um vocabulário controlado ou linguagem documentária utilizada pelo sistema documentário. Primeiro, o bibliotecário deve determinar o conteúdo que será representado para depois verificar se o vocabulário permite representar o assunto corretamente (LANCASTER, 2004).

\subsection{O Processo de Indexação}


É por meio da indexação que os acervos das bibliotecas são representados, via catálogo, o qual tem a função de aproximar o usuário do documento, pois o autor não emprega o mesmo vocabulário de quem fará uso do catálogo, sendo necessário haver coincidências entre as necessidades de busca e a representação do conteúdo. Por meio da recuperação da informação, o usuário também irá optar se quer ou não ter em mãos o documento encontrado.

O processo de indexação envolve um número variado de fases, sistematizadas conforme abordagem teórica de cada autor. No entanto, independente do número de etapas, o processo de indexação visa identificar o assunto de um documento e representá-lo através de conceitos, tendo como aporte termos advindos de um vocabulário controlado (Linguagem Documentária - LD; Linguagem de Indexação) ou não (Linguagem Natural - LN). Esse processo visa, portanto, à intermediação entre o documento e o usuário.

As linguagens documentárias são linguagens estruturadas e controladas, advindas de termos da linguagem de especialidade e da linguagem natural (linguagem do discurso comum), com o objetivo de representar a informação documentária para recuperá-la. (BOCCATO, 2009)

As linguagens documentárias visam à organização do conhecimento e correspondem às listas de cabeçalhos de assunto e aos tesauros e têm a função de representar o conteúdo dos documentos contidos em um sistema de recuperação da informação. Assim, possibilitam a recuperação da informação através de buscas formuladas pelos usuários.

Segundo Boccato (2009), as linguagens documentárias possuem um papel essencial nos processos de indexação e recuperação da informação, pois possibilitam a representação dos conteúdos documentários, o que facilita a busca por assunto realizada pelos usuários.

Essa representação efetuada a partir da análise do conteúdo do documento e, sua representação, realiza-se pela utilização de vocabulários controlados, os quais são construídos especialmente para padronizar e facilitar a entrada e a saída de dados em um sistema de informação. Essa padronização visa aumentar a precisão do sistema e, por extensão, sua eficácia e sua confiabilidade.

A utilização de vocabulários controlados permite representar o assunto do documento de modo consistente, e assim procuram aproximar o vocabulário usado pelo indexador das expressões usadas pelo usuário no momento da busca, de forma que o usuário elabore estrategicamente suas solicitações e alcance um bom resultado.

A recuperação da informação é, sem dúvida, a função mais importante de um catálogo de biblioteca, o que justifica a necessidade de se compreender como o catalogador executa a tarefa de análise de assunto, mantendo atenção na temática abordada no documento.

De acordo com Albrechtsen (1993, p. 220), existem três conceitos ou pontos de vista diferentes sobre análise de assunto: 
a) Concepção simplista - considera os assuntos como entidades simplistas absolutas, que podem derivar de uma abstração linguística do documento ou de dados que podem ser somados. Pela concepção simplista, analisar e indexar significa extrair automaticamente todas as palavras ou frases dos documentos a partir da frequência em que elas ocorrem no contexto da prática da indexação automática.

b) Concepção Orientada para o Conteúdo - envolve uma interpretação adicional do conteúdo, que vai além dos limites da estrutura léxica e gramatical, com o estabelecimento de assuntos que não estão explicitamente colocados no texto, mas que são facilmente identificados pelo indexador; envolve, portanto, uma abstração mais indireta do documento.

c) Concepção Orientada pela Demanda - considera o assunto numa perspectiva de transferência do conhecimento. Segundo essa concepção, os documentos são criados e deveriam ser tratados como instrumentos para transmissão de informações às pessoas interessadas. Ao analisar um documento, o indexador não deve se limitar a representar ou resumir apenas a informação explícita no documento, mais do que isso, deve perguntar-se: como eu poderia tornar esse conteúdo, ou parte dele, visível para o usuário potencial? Que termos deverei utilizar para levar esse conhecimento até o leitor interessado?

Ponderando a função de cada uma das etapas da indexação, pode-se dizer que uma das etapas consideradas mais importantes do trabalho do indexador é a análise de assunto, que tem como objetivo identificar e selecionar os conceitos que representam a essência de um documento.

A indexação diz respeito à identificação do conteúdo do documento, através do processo de análise de assunto, e à sua representação através de conceitos que, por sua vez, serão representados ou traduzidos em termos advindos de uma linguagem documentária. (FUJITA, 2003; FUJITA; RUBI, 2010).

Portanto, é evidente que a indexação é uma etapa fundamental no sistema de recuperação de informação, pois é nesta fase do processo que são delimitados os assuntos a serem indexados, utilizando-se os termos mais relevantes. Essa etapa precisa ser realizada de forma adequada para uma melhor recuperação da informação pelo usuário.

Os autores divergem quanto ao número de etapas da indexação. Porém, de acordo com Rubi (2008, p. 27) elas tratam basicamente das mesmas operações: a análise, em que é realizada a leitura e segmentação do texto para identificar e selecionar os conceitos; a síntese, que consiste na construção do texto documentário com os conceitos selecionados; e a representação, realizada por meio de linguagens documentárias.

No entanto, para que o processo de indexação seja realizado de forma adequada, fazse necessário aplicar ações baseadas em padrões com critérios de tratamento da informação, buscando aproximar os interesses entre quem disponibiliza e quem utiliza a informação.

Para atender de forma satisfatória as necessidades tanto das bibliotecas em disponibilizar as informações, quanto dos usuários que buscam informação, torna-se 
indispensável o desenvolvimento de políticas de indexação que apresentem diretrizes para o processamento consistente e adequado das informações.

\subsection{Políticas de Indexação}

As políticas de indexação são fundamentais para orientar o processo de indexação nas bibliotecas. Lancaster (2004) destaca que a política de indexação é um dos fatores que influi no desempenho de um sistema de recuperação da informação e que é diretamente atribuível à indexação.

Segundo Nunes (2004, p. 55), "política de indexação é uma diretriz que explicita as escolhas técnicas, que a biblioteca faz (e os bibliotecários precisam observar em suas rotinas), considerando fundamentalmente duas variáveis: o seu usuário e o seu acervo".

Cada biblioteca apresenta características específicas com relação ao seu acervo e sua a comunidade usuária, portanto, sua política de indexação deve contemplar critérios condizentes com estas particularidades visando tornar o processo de representação e recuperação da informação mais coerente e consistente.

O tratamento dos conteúdos informacionais recebe destaque quando determinado por políticas de indexação (LOUSADA et al., 2011). A política de indexação estabelece critérios e princípios que norteiam o bibliotecário nas decisões tomadas no processo de indexação, o que garante precisão na recuperação da informação. A indexação precisa de parâmetros que guiem os bibliotecários na tomada de decisões, reduzindo assim as incertezas durante o processo.

Uma política de indexação vai além de um procedimento técnico que estabelece parâmetros para a execução da indexação propriamente dita. Devemos ressaltar que a política de indexação não deve ser vista como uma lista de procedimentos a serem seguidos, e sim uma filosofia que reflete os interesses e objetivos da biblioteca (LOUSADA et al., 2011).

A política de indexação precisará ser elaborada como um documento oficial da biblioteca ou grupo de bibliotecas, que deve ser homologado pela direção, tornando-a permanente. A política deverá ser atualizada conforme as condições institucionais sofram alterações e conforme a evolução do conhecimento humano, processo que afeta a linguagem natural e as linguagens documentárias. Estes fatores fazem da política de indexação um instrumento dinâmico, em permanente atualização (NUNES, 2004).

Alguns objetivos de uma política de indexação são: i) Definição das variáveis que afetam o desempenho do serviço de indexação; ii) Estabelecimento dos princípios e critérios que servirão de guia na tomada de decisões para otimização do serviço; iii) Racionalização dos processos; iv) Consistência das operações envolvidas (STREHL, 1998).

Rubi (2008) destaca que a política de indexação deve refletir os objetivos da biblioteca, identificando condutas teóricas e práticas das equipes envolvidas no tratamento da informação da biblioteca visando definir um padrão de cultura organizacional coerente com a 
demanda da comunidade acadêmica interna e externa. A política de indexação precisa ser entendida como uma decisão administrativa, devendo estar descrita e registrada, para que possa ser avaliada e modificada, se preciso.

A política de indexação apoiada por um vocabulário controlado local possibilita maior aproximação às demandas específicas da instituição e fornece ao Sistema de Informação condições de desenvolver as atividades de representação temática dos documentos, de forma racional e consistente, para que o usuário recupere as informações certas em tempo hábil.

\section{PROCEDIMENTOS METODOLÓGICOS}

A pesquisa classifica-se como exploratória e qualitativa (SEVERINO, 2007), uma vez que busca explicitar o processo de indexação nas bibliotecas do IFPR. Configura-se também como uma pesquisa bibliográfica por coletar dados relevantes sobre o tema e dar o devido aporte teórico ao estudo. De acordo com Severino (2007, p. 122): “A pesquisa bibliográfica é aquela que se realiza a partir do registro disponível, decorrente de pesquisas anteriores, em documentos impressos, como livros, artigos, teses etc.".

Para melhor entendimento do tema proposto, realiza-se um estudo de caso, que consiste no estudo aprofundado e extenuante de um ou poucos objetos, de maneira que possibilite seu amplo e detalhado conhecimento (GIL, 2010).

O universo da pesquisa constitui-se de 12 bibliotecas, das 13 existentes, no IFPR. Uma biblioteca foi desconsiderada por se tratar do local de trabalho da autora deste estudo, visando manter a imparcialidade da pesquisa.

Utiliza-se como amostra os 5 bibliotecários que responderam o questionário. Como instrumento de coleta de dados, utilizamos um questionário composto por 10 questões com perguntas abertas, que "são aquelas que levam o informante a responder livremente com frases ou orações.” (BARROS, LEHFELD, 2007, p.106).

O questionário foi estruturado da seguinte forma: identificação do quadro de funcionários; identificação das atividades dos bibliotecários e serviços prestados pela biblioteca; levantamento sobre o processo de indexação realizado pelas bibliotecas; verificação da existência de uma política de indexação nas bibliotecas e quais itens deveriam ser contemplados por essa política. A coleta de dados ocorreu no período de novembro a dezembro de 2014. A entrega e recepção foi realizada por meio do formulário de questões do GoogleDrive, enviado para o e-mail dos bibliotecários.

\section{RESULTADOS}

Com relação à primeira questão, procurou-se identificar a quantidade de funcionários e a quantidade de profissionais bibliotecários presentes nas bibliotecas. Observa-se que o quadro de servidores é bem reduzido, no entanto, todas possuem bibliotecários. Este número reduzido de colaboradores das bibliotecas demonstra que certamente os bibliotecários tenham 
que desempenhar uma variedade maior de atividades no seu dia a dia, com exceção de uma das bibliotecas, que possui 3 bibliotecários justamente por ser a maior da rede.

QUADRO 1 - Caracterização das bibliotecas pesquisadas, com relação à quantidade de pessoal nas bibliotecas.

\begin{tabular}{|c|c|c|c|c|c|}
\hline Bibliotecas & Biblioteca 1 & Biblioteca 2 & Biblioteca 3 & Biblioteca 4 & Biblioteca 5 \\
\hline $\mathrm{N}^{\mathbf{o}}$ de Auxiliares & 0 & 5 & 3 & 1 & 2 \\
\hline $\mathrm{N}^{\mathbf{o}}$ de Bibliotecários & 2 & 3 & 1 & 1 & 1 \\
\hline Total de Colaboradores & $\mathbf{2}$ & $\mathbf{8}$ & $\mathbf{4}$ & $\mathbf{2}$ & $\mathbf{3}$ \\
\hline
\end{tabular}

Fonte: Dados da Pesquisa, 2014.

$\mathrm{Na}$ segunda questão, buscou-se identificar as atividades que os bibliotecários desenvolvem nas bibliotecas. Dentre as principais atividades citadas estão: catalogação; circulação de materiais; atendimento aos alunos; conferência de notas fiscais de materiais adquiridos; análise dos pedidos de compra de material bibliográfico solicitados pelos professores; divulgação dos serviços da biblioteca, através de folders, palestras, visitas orientadas e treinamento de usuários; planejamento da instalação do acervo; coordenação e supervisão das atividades da biblioteca; realização de reuniões com os coordenadores de curso, quando necessário; seleção de material bibliográfico para descarte e alienação; promoção de atividades de extensão (hora do conto, exposições, projetos de leitura); orientação na elaboração de trabalhos acadêmicos, segundo a ABNT; produção de relatórios anuais; providenciar dados estatísticos quando solicitados (Censo, IFPR em números); representar a biblioteca em eventos e reuniões; efetuar o acompanhamento de projetos; providenciar a manutenção das áreas físicas, instalações e equipamentos da biblioteca; restauração e a conservação física do acervo; atualização de dados (Facebook) da biblioteca.

Observa-se, de acordo com as respostas, que os profissionais se dividem entre atividades de tratamento da informação, gerenciais, serviço de referência, seleção e aquisição de materiais, dentre outras, e também são coordenadores do setor, o que sobrecarrega o bibliotecário, impedindo-o de dedicar-se com mais afinco a uma determinada tarefa que exige maior concentração e tempo, como, por exemplo, o processo de indexação.

Na questão 3, em relação aos serviços oferecidos, temos: 
QUADRO 2 - Serviços oferecidos pelas bibliotecas pesquisadas.

\begin{tabular}{|c|l|}
\hline $\begin{array}{c}\text { Bibliotecas } \\
\text { pesquisadas }\end{array}$ & \multicolumn{1}{|c|}{ Questão 3: Quais serviços vocês oferecem? } \\
\hline Biblioteca 1 & $\begin{array}{l}\text { "Atendimento aos usuários, empréstimo e recebimento de materiais, auxílio na normalização } \\
\text { de trabalhos acadêmicos, auxílio na pesquisa de base de dados." }\end{array}$ \\
\hline Biblioteca 2 & $\begin{array}{l}\text { "I - Circulação de material; II - Empréstimo entre bibliotecas; III - Ficha catalográfica; IV - } \\
\text { Levantamento bibliográfico; V - Normalização de trabalhos acadêmicos; VI - Treinamento de } \\
\text { usuários; VII - Reserva de material; VIII - Visita orientada." }\end{array}$ \\
\hline Biblioteca 3 & $\begin{array}{l}\text { "Empréstimo domiciliar; Empréstimo interbibliotecário; Orientação quanto ao uso das normas } \\
\text { de apresentação de trabalhos técnico-científicos; Solicitação de Levantamentos bibliográficos } \\
\text { e Comutação bibliográfica; Pesquisas de pronta-referência na Internet; Solicitação de compra } \\
\text { de materiais bibliográficos; treinamento para uso do portal capes." }\end{array}$ \\
\hline Biblioteca 4 & $\begin{array}{l}\text { "Empréstimo, devolução, renovação e consulta do acervo bibliográfico; orientação das } \\
\text { normas para pesquisa e desenvolvimento de relatórios, trabalhos de conclusão de curso, } \\
\text { monografias, dissertações e teses; orientação para pesquisa em base de dados; } \\
\text { microcomputadores para pesquisa." }\end{array}$ \\
\hline Biblioteca 5 & $\begin{array}{l}\text { "empréstimo; visita guiada; treinamento no sistema de bibliotecas para as turmas de primeiro } \\
\text { ano; treinamento no portal da CAPES para as turmas que irão iniciar o TCC; auxilio nas } \\
\text { normas da ABNT." }\end{array}$ \\
\hline
\end{tabular}

Fonte: Dados da Pesquisa, 2014.

Constata-se que os serviços oferecidos, na maior parte dos casos, são semelhantes entre as bibliotecas. Em razão da variedade de serviços prestados e o número reduzido de funcionários, certamente muitos desses serviços dependem dos bibliotecários para sua execução.

$\mathrm{Na}$ questão 4, procurou-se identificar as pessoas responsáveis pelo processo de indexação. Essa questão trouxe dados precípuos para a pesquisa, uma vez que procurou saber se cada biblioteca possui profissionais específicos para a função de indexador. Verificou-se que a indexação, em todas as bibliotecas, é realizada por um bibliotecário. Essa questão nos mostra que as bibliotecas sabem da importância da indexação, justamente por trabalharem com profissionais bibliotecários nessa prática, embora estes bibliotecários tenham que desenvolver também outras atividades dentro das bibliotecas.

Ao serem questionados sobre o que é determinante para uma indexação consistente (Questão 5), observa-se pelo relato dos sujeitos que apenas um deles considera importante levar em consideração o usuário no momento da indexação; um deles mencionou a importância de conhecimentos técnicos na área de biblioteconomia; outros dois mencionaram a importância da padronização e coerência na análise do assunto; enquanto que um deles foi um pouco ambíguo com relação a sua colocação, mencionando problemas com sistema de gerenciamento da biblioteca, mas ponderou sobre a análise documental e a utilização de outras instituições como base para determinação dos assuntos dos documentos.

Portanto nota-se que as bibliotecas atuam com consciência no processo de indexação e estão atentas para a relevância que a indexação traz para as bibliotecas. Entretanto ainda há melhoras a serem realizadas no que diz respeito a uma indexação efetiva. 
Entre os elementos observados para a análise de assunto de um documento, os bibliotecários (Questão 6) destacaram:

QUADRO 3 - Elementos observados pelos bibliotecários para a análise de assunto de um documento

\begin{tabular}{|c|l|}
\hline $\begin{array}{c}\text { Bibliotecas } \\
\text { pesquisadas }\end{array}$ & Questão 6: Quais os elementos você observa para análise de assunto de um documento? \\
\hline Biblioteca 1 & "Resumo do livro, sumário, introdução." \\
\hline Biblioteca 2 & "Prefácio, crítica, sumário e introdução." \\
\hline Biblioteca 3 & $\begin{array}{l}\text { "1) Determinação do assunto -estabelecimento de conceitos contidos no documento. 2) } \\
\text { Representação destes conceitos por uma linguagem de indexação." }\end{array}$ \\
\hline Biblioteca 4 & "A área de produção do documento e sua abrangência em relação aos possíveis usuários." \\
\hline Biblioteca 5 & "o assunto geral... depois os específicos." \\
\hline
\end{tabular}

Fonte: Dados da Pesquisa, 2014.

Observa-se que apesar de a questão anterior ter demonstrado que os profissionais atuam com consciência durante o processo de indexação, prevalece a ausência de procedimentos que envolvem o processo de análise de assuntos, que ocorre de forma superficial e mecanizada, o que demonstra que a qualidade desses produtos e serviços é comprometida. Os profissionais não mencionaram direcionamento para algum tipo de concepção de análise de assunto, porém percebe-se que se voltam para a informação explícita contida no documento e o método de indexação é pela via de extração, pois retiram os assuntos do livro, principalmente do sumário, para assim realizarem a representação do documento no catálogo da biblioteca.

Tendo como base os três conceitos ou pontos de vistas destacados por Albrechtsen (1993), sobre análise de assunto, percebe-se que a prática de indexação dos profissionais das bibliotecas do IFPR incide na preocupação de representar o assunto contido no documento, direcionando a análise de assunto pela Concepção Orientada para o Conteúdo. Não existe algum tipo de entendimento em como representar a informação implícita no documento, direcionada pela Concepção Orientada pela Demanda.

De maneira geral, cada profissional aplica uma forma de realizar a indexação, o que torna o processo agravante, visto que os bibliotecários passam a utilizar o bom senso profissional. Nesse sentido, entende-se que os aportes teóricos devam permear e direcionar a prática profissional, visando à diminuição de nuances ocorridas no momento da representação da informação.

Ao serem questionados sobre a utilização de algum instrumento que auxilie a questão da análise de assuntos como forma de controle e uniformização dos termos para a indexação nas bibliotecas (Questão 7), observa-se que 03 (três) deles utilizam os catálogos de outras bibliotecas, quais sejam: a Biblioteca Nacional (BN), a Rede Pergamum e a Biblioteca do Congresso, para extrair os assuntos abordados nos livros. Apenas dois relataram a utilização de tesauros para a identificação de termos para a indexação. 
É importante destacar que com o auxílio dos catálogos on-line os profissionais focam atenção em como o livro já foi cadastrado em outra biblioteca e não em como ele pode ser indexado a fim de atender as necessidades da comunidade usuária. Percebe-se que o processo de indexação se dissipa em meio às tecnologias que dão acesso à informação documentária criada por outra biblioteca.

A questão 8 procurou verificar a existência de instrumentos ou procedimentos préestabelecidos para atribuição de assuntos entre os profissionais que atuam na indexação das bibliotecas da rede do IFPR. Os relatos demostram que nenhuma biblioteca possui ou sequer embasa a atividade em alguma metodologia, manual, política ou qualquer diretriz específica para nortear as atividades de análise de assunto para indexação. Duas das bibliotecas relataram novamente a utilização do catálogo de outras bibliotecas como forma de padronizar e uniformizar o seu catálogo, procedimento que não estabelece nenhuma diretriz voltada para a realidade dessas bibliotecas.

Com relação à existência de uma política de indexação na biblioteca para orientar a tomada de decisões referentes à indexação (Questão 9), todos relataram não existir uma política que norteie o processo.

Ao serem questionados se consideram importante ter instrumentos (Política de Indexação, Vocabulário controlado, entre outros) para guiar e normatizar a representação de assuntos e quais os benefícios oriundos do estabelecimento de uma política de indexação específica para o contexto das bibliotecas dos Institutos Federais (Questão 10), obteve-se o seguinte:

QUADRO 4 - Benefícios de uma política de indexação segundo as bibliotecas pesquisadas.

\begin{tabular}{|c|l|}
\hline Bibliotecas & $\begin{array}{l}\text { Questão 10: Você considera importante ter instrumentos (Política de Indexação, } \\
\text { Vocabulário controlado, entre outros) para guiar e normatizar a representação de } \\
\text { assuntos? Quais os benefícios oriundos do estabelecimento de uma política de indexação } \\
\text { específica para o contexto das bibliotecas dos Institutos Federais? }\end{array}$ \\
\hline Biblioteca 1 & "Sim. O principal benefício é a unificação dos termos" \\
\hline Biblioteca 2 & $\begin{array}{l}\text { "É importante ter uma política. O estabelecimento de uma política proporcionará uma } \\
\text { padronização dos cabeçalhos e assuntos e autoridades, o que permitirá que a base do IFPR } \\
\text { (Pergamum) possa ser compartilhada por outras bibliotecas do Brasil. Desta forma, seria mais } \\
\text { um serviço a ser oferecido pelas nossas bibliotecas: o compartilhamento da base pela } \\
\text { internet." }\end{array}$ \\
\hline $\begin{array}{l}\text { "Sim. A política de indexação não deve ser vista como uma lista de procedimentos a serem } \\
\text { seguidos, e sim um conjunto de decisões que esclareçam os interesses e objetivos de um } \\
\text { sistema de informação e, particularmente, do sistema de recuperação da informação. } \\
\text { Infelizmente ainda não temos nada concreto neste sentido." }\end{array}$ \\
\hline Biblioteca 4 & $\begin{array}{l}\text { "Sou favorável a criação da política, respeitando o contexto de cada biblioteca e seus } \\
\text { usuários." }\end{array}$ \\
\hline Biblioteca 5 & $\begin{array}{l}\text { "É importante para a padronização que é conceito internacional, mas a indexação controlada é } \\
\text { muito generalista... é necessário ter uma indexação mais detalhada... e os instrumentos } \\
\text { utilizados como a BN, LC... já não permite." }\end{array}$ \\
\hline
\end{tabular}

Fonte: Dados da Pesquisa, 2014. 
Os bibliotecários compreendem a importância de uma política de indexação nas bibliotecas para resguardar o processo, pois é um aparato metodológico que subsidia a atividade de representação temática.

Quanto aos aspectos que devem ser contemplados pela política de indexação (Questão 11), os profissionais relataram:

QUADRO 5 - Aspectos que devem ser contemplados pela política de indexação segundo as bibliotecas pesquisadas

\begin{tabular}{|c|c|}
\hline $\begin{array}{l}\text { Bibliotecas } \\
\text { pesquisadas }\end{array}$ & $\begin{array}{l}\text { Questão 11: Em sua opinião, quais aspectos devem ser contemplados pela política } \\
\text { indexação? }\end{array}$ \\
\hline Biblioteca 1 & "Coerência e aproximação com a realidade dos usuários." \\
\hline Biblioteca 2 & "Forma de recuperação ou estratégias de busca." \\
\hline Biblioteca 3 & $\begin{array}{l}\text { "A política de indexação interessa a profissionais que realizam o tratamento temático de } \\
\text { documentos, aos gestores e dirigentes de sistemas de recuperação da informação, aos usuários } \\
\text { e aos próprios sistemas de informação. Acredito que isso deva ser uma discussão ampla para } \\
\text { determinar assim como a política de desenvolvimento de coleções, uma política de } \\
\text { indexação." }\end{array}$ \\
\hline Biblioteca 4 & "Padronização dos termos e normas, estratégias de busca claras e abrangentes, etc." \\
\hline Biblioteca 5 & $\begin{array}{l}\text { "que os sistemas permitam não somente a indexação formal... que se torna muito trabalhosa e } \\
\text { por isso mesmo os assuntos são limitados... não há uma exploração de assuntos mais } \\
\text { específicos que podem tornar as buscas com assuntos mais voltados para a linguagem do } \\
\text { nosso usuário. A linguagem formal tornam os assuntos mais geral e mais longe da realidade } \\
\text { da sala de aula..." }\end{array}$ \\
\hline
\end{tabular}

Fonte: Dados da Pesquisa, 2014.

Diante dos apontamentos feitos pelos profissionais, percebe-se que eles sabem da importância da política de indexação, porém alguns não possuem um entendimento muito claro de como é estruturada uma política. Nesse sentido, o estabelecimento de uma política, com procedimentos e instruções internas, torna-se necessária no contexto das bibliotecas do IFPR, por direcionar as ações dos profissionais bibliotecários e garantir a padronização do processo de indexação, considerando a realidade dessas bibliotecas e suas características específicas.

\section{CONSIDERAÇÕES FINAIS}

No caso dos Institutos Federais, em decorrência da diversificação de seus usuários, evidencia-se o fato dos catalogadores dessas bibliotecas terem que representar tematicamente os documentos a fim de atender as diversas necessidades da comunidade usuária.

No caso das bibliotecas do IFPR, foi possível verificar a inexistência de critérios e diretrizes para a atribuição de assuntos, bem como a ausência de uma análise de assuntos orientada pelo conteúdo e pela demanda de seus usuários. As bibliotecas atualmente utilizam como embasamento a indexação de outras bibliotecas, ou seja, os assuntos são atribuídos de acordo com os termos utilizados nos catálogos on-line de outras instituições com realidades e públicos diferentes do público do IFPR. 
A consulta em outros catálogos pode auxiliar o profissional quando houver dúvidas em determinada temática do documento, no entanto o direcionamento que é dado na indexação de cada biblioteca deve ser variável, de acordo com a área de domínio coberta pelo acervo, a demanda da comunidade usuária que atende e a política de indexação do sistema documentário.

Diante dessa realidade, é importante salientar que os procedimentos que pertencem à indexação devem ser entendidos como um processo intelectual de análise de conteúdo e representação, não apenas se restringirem a uma tarefa de cópia de cadastros de outras bibliotecas.

Portanto, para o profissional alcançar a finalidade do processo, compreende-se que devam existir procedimentos a serem seguidos, ou seja, torna-se evidente a necessidade de sistematização do processo de indexação e também da própria atuação bibliotecária. Por sua vez, essa sistematização só poderá ser alcançada à medida que as bibliotecas do IFPR possuam sua própria política de indexação que apoiada por um vocabulário controlado local, possibilitará maior aproximação às demandas específicas da instituição. $\mathrm{O}$ processo de indexação é uma atividade complexa e as normas e políticas dão suporte ao profissional, amparando-o na execução da tarefa, ao invés de adotar a perspectiva do bom senso.

Os bibliotecários, ao realizarem a indexação, devem se apoiar no aporte teórico e metodológico advindo da Ciência da Informação, atentando-se às etapas do processo de representação temática e observando a rotina diária de trabalho, em que o uso das tecnologias facilitam o tratamento e a disponibilização da informação documentária, porém não substituem o processo de indexação realizado pelo profissional.

Deve-se repensar criticamente a prática profissional e as competências que estão sendo aplicadas na análise e representação temática. Percebe-se que deve ser remetida mais atenção ao tratamento do material informacional, atentando-se sempre para o objetivo do processo: a recuperação da informação.

\section{REFERÊNCIAS}

ALBRECHTSEN, Hanne. Subject analysis and indexing: from automated indexing to domain analysis. The Indexer, London, v.18, n. 4, p. 219-24, 1993. Disponível em: <http://www.theindexer.org/files/18-4/18-4_219.pdf> Acesso em: 20 ago. 2014.

\section{BARROS, Aidil Jesus da Silveira, LEHFELD, Neide Aparecida de Souza. Fundamentos de metodologia científica. 3.ed. São Paulo: Pearson: Prentice Hall, 2007.}

BOCCATO, Vera Regina Casari. A linguagem documentária vista pelo conteúdo, forma e uso na perspectiva de Catalogadores e usuários. In: FUJITA, Mariângela Spotti Lopes. (Org.). A indexação de livros: a percepção de catalogadores e usuários de bibliotecas universitárias. São Paulo: Cultura Acadêmica, 2009. p. 19-42. Disponível em: <http://books.scielo.org/id/wcvbc/pdf/boccato-9788579830150-08.pdf> Acesso em: 20 ago. 2014. 
BRASIL. Lei n ${ }^{\circ}$ 11.892, de 29 de dezembro de 2008. Institui a Rede Federal de Educação Profissional, Científica e Tecnológica, cria os Institutos Federais de Educação, Ciência e Tecnologia, e dá outras providências. Diário Oficial da União, Brasília, DF, 30 dez. 2008. Disponível em: <http://www.planalto.gov.br/ccivil_03/_ato2007-2010/2008/lei/111892.htm>. Acesso em: 15 ago. 2014.

FUJITA, Mariângela Spotti Lopes. A identificação de conceitos no processo de análise de assunto para indexação. Revista Digital de Biblioteconomia e Ciência da Informação, Campinas, v. 1, n. 1, p. 60-90, jul./dez. 2003. Disponível em: $<$ http://www.sbu.unicamp.br/seer/ojs/index.php/rbci/article/view/287/167>. Acesso em: 20 ago. 2014.

FUJITA, Mariângela Spotti Lopes, RUBI, Milena Polsinelli. Política de indexação na catalogação de assunto em bibliotecas universitárias: a visão sociocognitiva da atuação profissional com protocolo verbal. Revista Digital de Biblioteconomia \& Ciência da Informação, Campinas, v. 7, n. 2, p. 118-150, jan./jun. 2010. Disponível em: <http://www.brapci.ufpr.br/download.php?dd0= 10572> Acesso em: 20 ago. 2014.

FUJITA, Mariângela Spotti Lopes; RUBI, Milena Polsinelli; BOCCATO, Vera Regina Casari. As diferentes perspectivas teóricas e metodológicas sobre indexação e catalogação de assuntos. In: FUJITA, M. S. L. (Org.) A indexação de livros: a percepção de catalogadores e usuários de bibliotecas universitárias. São Paulo: Cultura Acadêmica, 2009. p. 19-42.

Disponível em:

$<$ http://www.esalq.usp.br/biblioteca/PDF/a_indexacao_de_livros_a_percepcao_de_catalogad ores_e_usuarios_de_bibliotecas_universitarias.pdf> Acesso em: 20 ago. 2014.

GIL, Antônio Carlos. Como elaborar projetos de pesquisa. 5.ed. São Paulo: Atlas, 2010.

HOFFMANN, Wanda Aparecida Machado, BOCCATO, Vera Regina Casari, SANTOS, Cintia Almeida da Silva. O profissional da informação nos Institutos Federais de Educação, Ciência e Tecnologia: um estudo de percepção. Revista EDICIC, v.1, n.3, p.127-142, Jul./Sep. 2011. Disponível em: <http://200.136.214.89/nit/refbase/arquivos/hoffmann/2011/621_Hoffmann_etal2011.pdf> Acesso em: 15 ago. 2014.

INSTITUTO FEDERAL DO PARANÁ. Pró-reitoria de Planejamento e Desenvolvimento Institucional (Proplan/IFPR). Mapa dos Campus IFPR. 2014. Disponível em: $<$ http://info.ifpr.edu.br/informacoes-gerenciais-e-estatisticas-educacionais/relacao-decampus-2/> Acesso em: 15 set. 2014.

LANCASTER, Frederick Wilfrid. Indexação e resumos: teoria e prática. 2. ed. Brasília, DF: Briquet de Lemos/Livros, 2004.

LOUSADA, Mariana et al. Políticas de indexação no âmbito da gestão do conhecimento organizacional. Informação e Sociedade, João Pessoa, v. 21, n. 1, p.191-202, jan./abr. 2011. Disponível em: <http://www.ies.ufpb.br/ojs2/index.php/ies/article/view/ 4136/5607>. Acesso 
em: 15 set.. 2014.

MAIMONE, Giovana Deliberali, SILVEIRA, Naira Christofoletti, TÁLAMO, Maria de Fátima Gonçalves Moreira. Reflexões acerca das relações entre representação temática e descritiva. Informação \& Sociedade: Estudos, João Pessoa, v.21, n.1, p. 27-35, jan./abr. 2011. Disponível em: < http://www.ies.ufpb.br/ojs2/index.php/ies/article/view/7367/5596> Acesso em: 17 set. 2014.

NUNES, Claudio Omar Iahnke. Algumas considerações acerca da ausência de políticas de indexação em bibliotecas brasileiras. Biblos, Rio Grande, v.16, p. 55-61, 2004. Disponível em: <www.brapci.ufpr.br/download.php?dd0=11141> Acesso em: 15 set. 2014.

RUBI, Milena Polsinelli. Política de indexação para construção de catálogos coletivos em bibliotecas universitárias. Marília: Unesp, 2008. Tese (Doutorado) - Programa de PósGraduação em Ciência da Informação - Universidade Estadual Paulista (Unesp). Disponível em:<http://base.repositorio.unesp.br/bitstream/handle/11449/103388/rubi_mp_dr_mar.pdf?se quence=1> Acesso em: 17 set. 2014 .

SEVERINO, Antonio Joaquim. Metodologia do trabalho científico. 23. ed. São Paulo: Cortez, 2007.

STREHL, Letícia. Avaliação da consistência da indexação realizada em uma biblioteca universitária de artes. Ciência da Informação. Brasília, DF, v.27, n.3, p.329-335, set./dez. 1998. Disponível em: <http://www.scielo.br/pdf/ci/v27n3/27n3a11.pdf> Acesso em: 17 set. 2014.

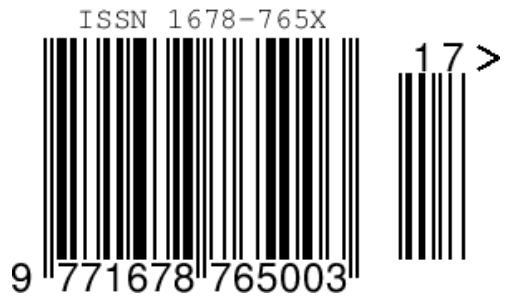

FERREIRA, Fabiane; CERVANTES, Brígida Maria Nogueira. Processo de indexação nas bibliotecas dos Institutos Federais do Paraná - IFPR. RDBCl: Revista Digital de Biblioteconomia e Ciência da Informação, Campinas, SP, v. 14, n. 1, p. 164-179, fev. 2016. ISSN 1678-765X. Disponível em: <http://periodicos.sbu.unicamp.br/ojs/index.php/rdbci/article/view/8640985>. Acesso em: 01 fev. 2016. doi:http://dx.doi.org/10.20396/rdbci.v14i1.8640985. 